\title{
Community-Based Coastal Resource Management (CB-CRM): a Case Study f Mariveles, Bataan, Philippines
}

\author{
ANDREW LOU L. MUNGCAL
}

\begin{abstract}
This paper addressed the issue of sustainable coastal resource management through a successful Community-Based Coastal Resource Management (CB-CRM) Program in the Municipality of Mariveles, province of Bataan in the Philippines. The paper investigated how governance and institutional and legislative framework, and the concept of sustainable development complemented each other to promote good local eco-governance in the management and protection of finite local marine resources. Specifically, it analyzed how the local fisherfolk community of Mariveles utilized efficiently their finite marine resources in the context of eco-governance. It also investigated how the cooperative efforts of various stakeholders: peoples' organizations (POs), local government unit (LGU), and a non-government organization (NGO) in Mariveles, Bataan affected their coastal resources against environmental degradation and exploitation. This paper would benefit POs, LGUs, and NGOs in their quest for sustainable management and conservation of their limited coastal resources. This paper yielded the following findings. First, POs and NGOs engage when NGOs can strengthen the POs' capacity building through the transfer of skills and technology,when NGOs can enhance the POs' indigenous knowledge, and when NGOs are more knowledgeable of formal venues of LGU participation. Second, LGUs, NGOs and POs engage when POs and NGOs can complement each other to strengthen their capacity building, and when NGOs can help implement environmental programs that are beneficial to the POs. Third, NGOs and POs engage when POs are threatened by elite power, and when NGOs want their environmental issues on LGU's legislative agenda. Finally, NGOs and POs engage when they see possible LGU cooperation. Participant observation through focus group discussion (FGD) and key informants' interview of different stakeholders was a primary source of information in formulating the aforementioned conclusions. In addition, stakeholders' analysis and documentary analysis, i.e., books, print and non-print materials, video footage, monograph, were used as secondary sources of information. The author is solely responsible for any information found in this paper.
\end{abstract}

\section{Keywords: Community-based Coastal Resource Management, Sustainable Development, Eco-governance}

\section{INTRODUCTION}

Sustainable development is the strategy of both developed and developing marketoriented and centrally-planned economies to meet the needs of the present without compromising the ability of future generations to meet their own needs. It requires economic growth, demographic balance, preservation and conservation of resources, risk-free technology, environmental governance, at the same time, it guarantees equitable opportunities for all.

Correspondence : Andrew Lou L. Mungcal, Department of Anthropology, University of the Philippines-Diliman, Quezon City (City University of Makati), Philippines.
These improvements in the over-all quality of life of people must be in harmony with the ecological balance of the natural environment. To guarantee sustainable development despite inequalities in the allocation of political and economic power, local interdependence and international cooperation shall be encouraged (World Commission on Environment and Development, 1987).

This paper addressed the issue of sustainable coastal resource management through the successful Community-Based Coastal Resource Management (CB-CRM) in Mariveles, Bataan. This initiative by multistakeholders paved the way for the passage of the Philippine Fisheries Code of 1998 (PFC) 
or Republic Act No. 8550 (RA 8550), and the creation of the Fisheries and Aquatic Resources Management Councils (FARMCs). In 1992, the Cooperative Development Program (CDP) of the Institute of Social Order (ISO), an environmental non-government organization (NGO), started as a means to empower the marginalized fishermen and peoples' organizations (POs) of Bataan through community organizing.

In 1995, this NGO-PO partnership was followed by a series of research studies by ISO to address the real problem involved in the protection and management of local marine resources. From this, the CB-CRM Program in Mariveles was embarked on the coastal rural municipality of Mariveles. By 1998, with the support of the Mariveles-local government unit (LGU), a strong LGU-PO-NGO relationship was established through the adoption of the Philippine Fisheries Code and the creation of the FARMCs. At this time, the ISO was phasing out from a successful CBCRM Program in Mariveles.

\section{MATERIALS AND METHODS}

This paper was all about a historical case. The case study method was used to describe the process of utilizing and sustaining the finite marine resources of Mariveles through the adoption of a CB-CRM Program. The descriptive study traced the history and the experiences in policy formulation, implementation and monitoring from the point of view of the different stakeholders. The case study focused on the experiences and strategies of the Institute of Social Order and the Bantay Dagat (BD) or organized local fishermen of Mariveles.

In a stakeholders' analysis, the social players, as well as their interests and motives, their roles, and the means by which they articulate their roles are all identified in the policy formulation, implementation and monitoring. The methodology accounted for the rationale, the strategies, and the interests of different social players who acted upon a CBCRM Program in Mariveles.

\section{Data Gathering And Collection} Techniques. Participant observation through focus group discussion (FGD) among the marginalized local fishermen and peoples' organizations, and key informants' interview of different stakeholders was utilized as a primary source of information in analyzing a CB-CRM Program in Mariveles. In addition, stakeholders' analysis and documentary analysis, i.e., books, print and non-print materials, video footage, monograph, were used as secondary sources of information.

Governance And Institutional And Legislative Framework. The United Nations (UN) defines "governance systems as the framework of social and economic systems, legal and political structures within which humanity organizes itself." In addition, "governance can be defined as the process by which stakeholders articulate their interest, their input is absorbed, decisions are taken and decision makers are held to account." Governance includes the following indicators: participation of civil society, decision making process with formal and informal actors' involvement, rule of law, transparency, responsiveness, consensus, equity and inclusiveness, effectiveness and efficiency, and accountability. In the Philippine setting, "environmental governance derives from the application of governance concept, framework and strategies and it denotes the interactive processes of decision making and power relations among the stakeholders" (Mangada, 2004).

The 1987 Philippine Constitution provides the basic legal framework for the protection and preservation of the country's marine wealth, with the ultimate control and ownership of its natural resources in its archipelagic waters, territorial sea, and exclusive economic zone. The Constitution provides explicit recognition of the need of Coastal Resource Management, linking its application to optimum productivity, sustainability, and equity through democratic processes and distributive justice. It also recognizes the obligation of the state to protect, develop and conserve marine resources and to protect the right of 
subsistence fishers, especially local communities. The Constitution encourages non-governmental community-based organizations to promote the welfare of the country" (Mangada, 2004).

Furthermore, "the Philippine Congress passed the 1991 Local Government Code (LGC) or Republic Act No. 7160 (RA 7160) which paved the way for local autonomy and self-reliance of local communities. The passage of the LGC resulted in a structural power shift that placed local coastal governments and cities at the forefront of sustainable resource management. It provided for the devolution and decentralization of authority from national government agencies to provincial and municipal governments, including coastal and marine resource management. Municipalities benefited because their municipal waters were extended from seven (7) to fifteen (15) kilometers from the shore" (Mangada, 2004).

Moreover, "the Philippine Fisheries Code of 1998 (PFC) or Republic Act No. 8550 (RA 8550) provides for the development, management and conservation of fisheries and aquatic resources. It integrates all laws relevant to fisheries. It recognizes the importance of rational and sustainable development, management and conservation of fisheries and aquatic resources. This is to be consistent with the primary objectives of maintaining a sound ecological balance, and protecting and enhancing

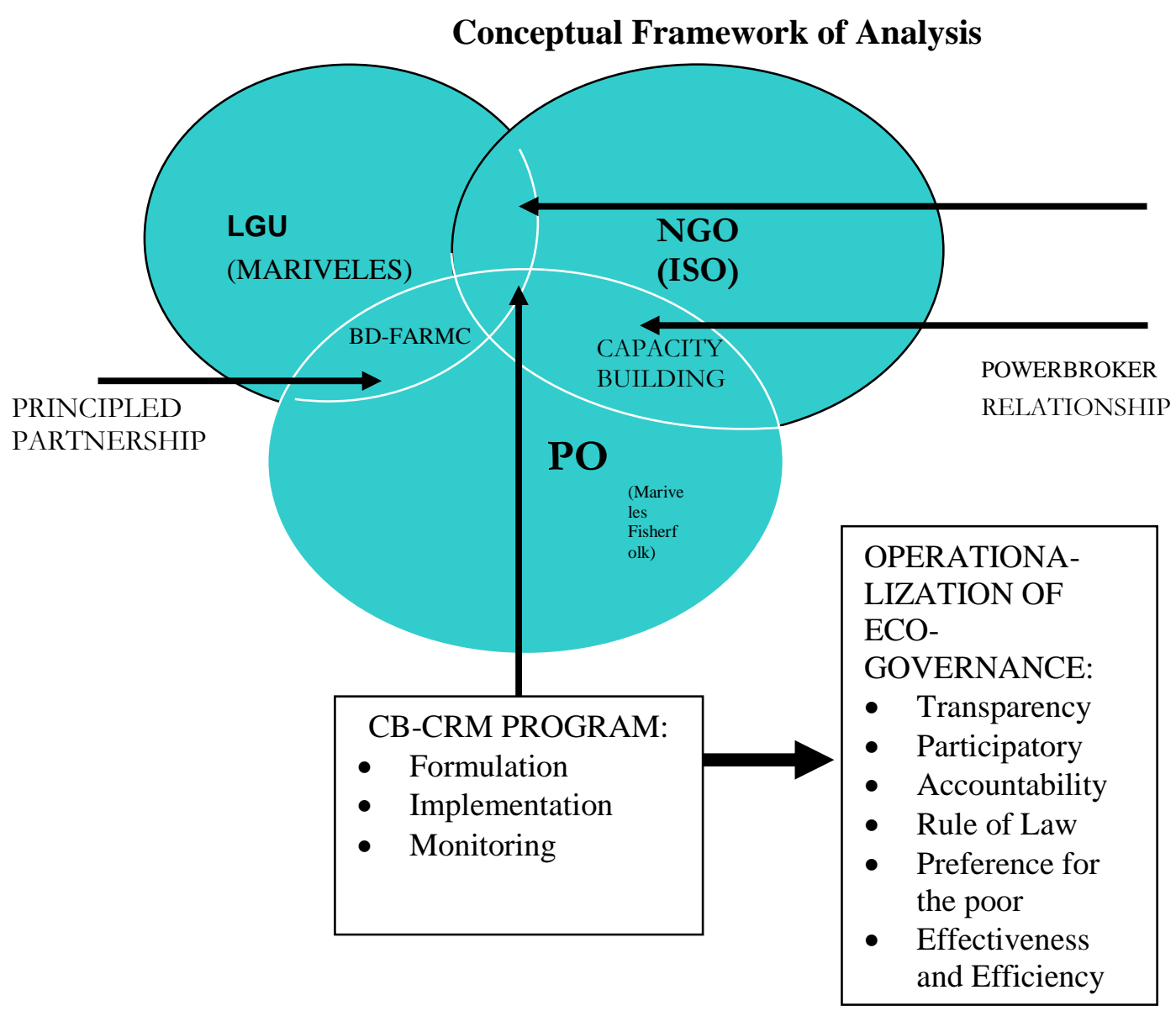

Figure 1. Operationalization of Eco-Governance through Multi-Stakeholders' Approach

the quality of the environment. The Philippine Fisheries Code (PFC) specifies the application of integrated coastal area management and the provision of a sound 
policy and institutional framework for fisheries resource management and its long term sustainability" (Mangada, 2004).

This study operationalized the concept of eco-governance through the LGU-NGO-PO collaboration or engagement in the formulation, implementation and monitoring of a CB-CRM Program in Mariveles. A CBCRM Program in Mariveles built a principled partnership between the Mariveles-LGU and the local fisherfolk community through the establishment of the Bantay Dagat-Fisheries and Aquatic Resources Management Council (BD-FARMC). It also produced a powerbroker relationship between the Mariveles-LGU and the ISO. Most importantly, it strengthened the capacity building of the local fisherfolk community of Mariveles in the management and protection of their finite marine resources through the assistance of the ISO. A CB-CRM Program in Mariveles was a clear example of an environmental issue to promote good local eco-governance which includes the following indicators derived from Mangada (2004): transparency, participatory (or participation of civil society and decision making process with formal and informal actors' involvement as used by Mangada), accountability, rule of law, preference for the poor (or equity and inclusiveness as used by Mangada), effectiveness and efficiency.

Brillantes Jr. (2001) defined these indicators of local governance as follows. (1) Transparency requires the availability of reliable information and the provision of appropriate, necessary and relevant information to stakeholders when needed and upon demand. (2) Participatory means the partnerships with civil society and the provision of a voice for all stakeholders in the formal and informal decision making processes. (3) Accountability is present when decision makers are answerable for their actions and violators are penalized accordingly. (4) Rule of law exists when legal systems are in place and a stable and legal framework is fairly and impartially enforced. (5) Preference for the poor requires the availability of local poverty alleviation programs and the manifest bias to address the pervading problem of poverty in the community. (6) Effectiveness and efficiency means the achievement of maximum output at the lowest cost (Alfiler, 2003) or the productive allocation and distribution of scarce resources with little waste.

\section{A Case Study Of MarivelesProfile of} Mariveles. Mariveles is a municipality of the province of Bataan located in the southernmost tip of the Bataan Peninsula. It is approximately one hundred and seventythree (173) kilometers from Manila and about fifty (50) kilometers from the provincial capital of Balanga. Mariveles is bordered on its eastern side by Manila Bay, which cuts across the south side of the municipality, and at the same time, engulfing the nearby island of Corregidor. It is bounded on the west by the Bagac Bay, which extends up to the South China Sea, and on the north, by the municipality of Limay. It has a total land area of 15,919.86 hectares. At least $11,060.43$ hectares of this area are used as pasture lands, 1,038 hectares for agriculture, 3,129.46 hectares for forest reserve, 518.14 hectares for residential purposes, and 173.82 hectares for industrial use. Its topography seems inappropriate to the extensive agricultural land-use development. It has a deep, fine harbor, which is protected from the harshness of the sea by the Corregidor Island (Rosal, 1999).

By sea, Mariveles is a one-hour and fifteen minutes journey from Manila Bay to its port. The Municipality of Mariveles, historically called the Village of Kamaya, is a haven in the southern tip of Bataan Peninsula because of its proximity to the mouth of Manila Bay, and it hosts the Bataan Export Processing Zone (BEPZ). It has twelve coastal barangays (town) and six inland barangays wherein the small population makes a living from traditional fishing and farming. In the poblacion (town center), people just walk or ride on jeepneys and tricycles. Life is so simple because in just less than ten minutes, people can travel from their homes to the BEPZ, the municipal 
hall, the public market, and even down to their humble barako or motor boats.

Historical Context of A Cb-Crm Program. A CB-CRM Program in the Municipality of Mariveles was a concerted effort among various stakeholders: the local government unit (LGU), peoples' organizations (POs), and a non-government organization (NGO) to manage efficiently and protect effectively their finite marine resources against environmental degradation and exploitation.

The Institute of Social Order (ISO), an environmental NGO, facilitated a CB-CRM Program in Mariveles through the transfer of skills and technology to promote and improve the capacity building of the Mariveles fisherfolk community in the efficient management and effective protection of their finite coastal resources.

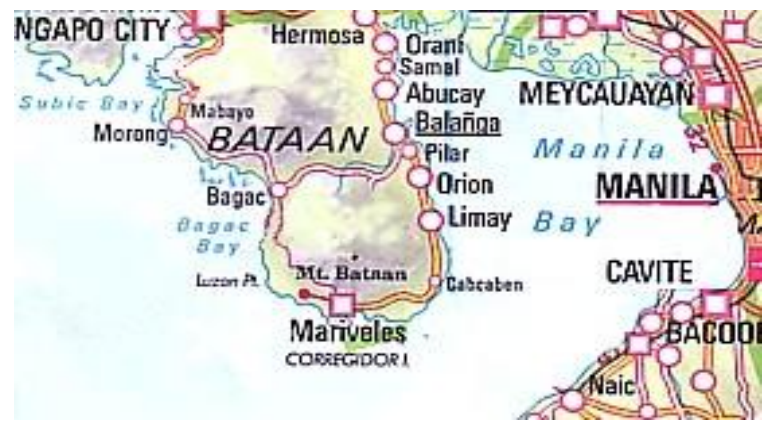

Figure 2. Location Map of Mariveles

In 1991, the ISO initiated the Cooperative Development Program (CDP) in the province of Bataan to provide livelihood assistance and to empower the marginalized fisherfolk through community organizing. It organized local fishermen into peoples' organizations (POs), and in turn, these POs formed into federations. The ISO helped establish these POs into the Bigkis Bisig ng Mangingisda sa Bataan (BBMB), a federation of POs from three municipalities of the province of Bataan. Despite ISO interventions, the livelihood of the local fisherfolk community was not sustained because the problems are deeper and more complex.

In 1995, the ISO conducted three research studies to find out the reasons behind these problems. First, it initiated the Participatory
Rapid Appraisal (PRA) to extract sociological data in Mariveles. As a consequence, the ISO found out that the local community of Mariveles was not aware of their finite marine resources. This open access of Mariveles municipal waters endangered the coastal resource base of the local fisherfolk community. Many fishermen resorted to dynamite and cyanide fishing which are destructive to coral reefs, mangroves and marine life preservation.

Second, ISO undertook a Resource Ecological Assessment (REA) to study the marine resources of Mariveles. It found out that it had reached a sub-critical level. This means that there was a genuine threat to coral reefs and mangroves. ISO, with the help of the local fishermen of Mariveles, realized that commercial fishing was the reason behind this destruction of local marine resources. Large commercial fishing vessels that operated from the cities of Malabon and Navotas in Metro Manila were responsible for illegal fishing activities, and they violated the fifteen kilometers limit from the shoreline of Mariveles to the open municipal waters in the mouth of Manila Bay that prohibit commercial fishing around the area.

Third, ISO came out with the Legal Institutional Study (LIS) to assess policies of illegal fishing and their implementation. It found out that there were no municipal ordinances. It also learned that the Philippine National Police (PNP) Maritime Command was ineffective in implementing Presidential Decree Number 704 (PD 704) or otherwise called the Fisheries Code of the Philippines, which was in effect since 1975, because it favored commercial fishing more than the marginalized fishermen of coastal areas in the Philippines. The absence of penal sanctions under the law and municipal ordinances to protect the municipal waters against commercial fishing aggravated the problem of protecting the finite marine resources in Mariveles.

Findings Of The Study. From the studies abovementioned, the ISO initiated a CB-CRM Program in Mariveles. It deepened the roots of $\mathrm{PO}$ organizing and strengthened 
the POs' capacity building through a series of seminars and trainings for the marginalized fishermen of Mariveles. These seminars and trainings of about twenty to thirty times included the following: basic leadership training, local community organizing, bookkeeping, communication and team building. The transportation, food, boarding and lodging expenses of fishermen who participated were shouldered by the ISO alone.

Furthermore, the ISO was also responsible in creating cooperatives for the POs which includes the following: Samahang Maglalambat ng Pinag-apugan (SMP), Pinag-apugan Women's Marketing Cooperative (PWMC), Bigkis Bisig ng Mangingisda sa Bataan (BBMB), and Alyansa. The PWMC, composed of the active wives of the marginalized fishermen, provides fishing supplies, e.g., gasoline while the BBMB, a PO federation, trades rice, a local staple food, through the aid of the Philippine National Food Authority (NFA).

Moreover, the ISO facilitated the creation of Bantay Dagat (BD) Movement or organized PO leaders from the marginalized fishermen of Mariveles. The Bantay Dagat (BD) became the official arm of the Municipality of Mariveles in the implementation and monitoring of its municipal ordinances against commercial fishing. The lack of awareness and consciousness of the marginalized fishermen and the absence of municipal ordinances of Mariveles to protect its finite marine resources led to the environmental degradation and exploitation of its coastal resource base.

In 1996, the ISO and the BD drafted a municipal ordinance to prohibit illegal fishing in Mariveles. The Sangguniang Bayan (SB) or local legislative council of Mariveles approved the municipal ordinance. The local legislative ordinance had many limitations. First, Presidential Decree No. 704 (PD 704) which imposes lenient penalties was used as the guideline for fishing violators. Second, the 1991 LGC limited the penalties and fines of convicted illegal fishers. Instead of imposing the limit of two thousand and five hundred (2,500) pesos per violation, the ISO and the BD formulated a fine of two thousand and five hundred $(2,500)$ pesos per violator. The Mariveles-LGU at that time led by Mayor Oscar delos Reyes did not even participate in the formulation of the municipal ordinance. It seemed that they were not ready to empower the POs and support the ISO as active partners in local development. It would take another local election in Mariveles before the constructive and principled partnership among the stakeholders would become possible.

Fortunately, in the same year, Philippine President Fidel Ramos signed Executive Order No. 240 (EO 240) creating the organization of Fisheries and Aquatic Resources Management Councils (FARMCs) in drafting fishery ordinances and monitoring Bantay Dagat (BD) ad hoc committees. In fact, it was the Bureau of Fisheries and Aquatic Resources (BFAR) Region III that sponsored trainings and seminars of the BDFARMC instead of the Sangguniang Bayan (SB). On a positive note, Mayor delos Reyes passed a municipal ordinance that gives seventy percent $(70 \%)$ of the collected fines to the BD operation while thirty percent only remained to the Mariveles-LGU.

In 1998, new developments took place in the national government and the MarivelesLGU. The Philippine Congress passed Republic Act No. 8550 (RA 8550) or the Philippine Fisheries Code of 1998 (PFC) to address the problem of the limitless exploitation of the coastal resources by conglomerate commercial fishers.

In May 1998, the people of Mariveles elected a new local chief executive (LCE), Mayor Angel Peliglorio, Jr. In the following years, the people proved that they had made a prudent choice in electing this man. Only two days in office, Mayor Peliglorio approved the petition of the ISO and the BD to allocate one hundred and six thousand $(106,000)$ pesos to the administration and organization of Mariveles-Fisheries and Aquatic Resource Management Council (M-FARMC). This 
was evident in the signing of a Memorandum of Agreement (MOA) between the LGU, POs, and the ISO. The SB Chairman, as a member of the M-FARMC that represented the mayor, was crucial in this new partnership.

In May 1997, PO leaders, the ISO, the Mariveles-LGU, the Department of Agriculture (DA), and other concerned citizens of Mariveles met in Deep Spring Resort for the FARMC Summit. They created the M-FARMC ad hoc committee and elected the M-FARMC officers. The same BD organizers were elected in the MFARMC. The problems of the marginalized fishermen of Mariveles did not end in the creation of the M-FARMC. M-FARMC officials are limited only to drafting fishery ordinances in the Sangguniang Bayan (SB) of Mariveles, and monitoring $\mathrm{BD}$ committees.

Also, because of the openness of Mayor Peliglorio, the M-FARMC received a loan from the Mariveles-LGU of fifty thousand $(50,000)$ pesos to buy two (2) patrol boats and another fifty thousand and two $(50,002)$ pesos to buy radios for communication to be used during $\mathrm{BD}$ operations in Mariveles municipal waters.

Furthermore, the PNP-BD operation was successful in apprehending violators of fishery ordinances. Mariveles Police Chief cited statistics from January 31 to May 1999 that led to the arrests of illegal commercial fishers. One thousand six hundred and twelve $(1,612)$ persons were arrested because of violations. One thousand and two $(1,002)$ motorized boats were impounded. Fifty (50) kilos of fishing paraphernalia were confiscated. A case was filed in a judicial court while one hundred and one (101) persons were fined.

In addition, M-FARMCs through the BD, the arm of M-FARMC in the implementation process, filed two hundred and forty nine (249) cases in the judicial courts in 1998, three hundred and sixty one (361) cases in 1999, and eighty eight (88) cases in 2000 against commercial fishers. In August 2000, the M-FARMC won a legal battle by the conviction of an illegal fisher. Unfortunately, three (3) cases were dismissed because of the absence of FAOs and municipal ordinances to prosecute illegal fishers.

On the other hand, there were also setbacks. Problems in the implementation and monitoring of commercial fishing still remained. Many times, BD operations led to the filing of charges against the BD members by commercial fishers. One time, violators sued and made counter-charges against local fishermen and two PNP escorts on the grounds of extortion. The local fishermen and their PNP escorts were arrested and litigated in the judicial courts of Metro Manila for implementing the municipal ordinances of Mariveles.

As a consequence, the paralegal support of the ISO was very important in addressing this problem. The BD-FARMC also tapped the support of the University of the Philippines (UP) lawyers. They were generous to assist the marginalized fishermen to defend themselves against counter-charges made by commercial fishers in the judicial courts.

Moreover, BD-FARMC members who are deputized in the operations against illegal fishing are limited to both logistical and legal support. The Philippine National Police (PNP) Maritime Command officers who are charged to escort BD members are co-opted by commercial fishers through bribery. Some PNP officers are protectors of commercial fishers who bribed these police officers in return. In fact, in Barangay Puerto Baler, a town in Mariveles, the BD apprehended commercial fishermen inside the fifteenkilometer municipal waters. However, the PNP officers requested the BD to drop the charges in exchange of fish catch.

Also, the lack of some Fisheries Administrative Orders (FAOs) of the Implementing Rules and Regulations of the Philippine Fisheries Code, specifically the use of fine mesh net in Rules 89.1, 89.2 and active gear in Rule 90.1, made impossible to litigate violators of municipal ordinances. Notably, the Bureau of Fisheries and Aquatic Resources (BFAR) under the Department of 
Agriculture is in-charge in the issuance of these FAOs. In August 2000, the BFAR issued FAO 201 prohibiting the use of active gear in municipal waters, bays, and fishery management areas.

Though a CB-CRM Program in Mariveles was effective in sustaining the finite marine resources of the local fisherfolk community, however, this is not sufficient without a supplemental livelihood for the local fishermen. In fact, a family of seven has to get an extra income in order to sustain their daily expenses by baking puto (local bread) and by rationing vinegar (local spice) in the morning while the head of the family has to drive a tricycle, a three-wheel vehicle, after fishing.

Operationalization of Indicators of Eco-Governance. At first, the local fisherfolk community of Mariveles was not aware of the limitations of their marine resources. They used dynamite and cyanide fishing and other destructive forms in destroying the coral reefs and mangroves of Mariveles municipal waters. The bottom line here is the endemic poverty of the marginalized fishermen of Mariveles. They need a sustainable source of income to survive in their everyday living. Almost all these fishermen have no college education so they have no choice but to undertake various ways to maximize their income through fishing. They were not conscious that their source of livelihood could threaten their finite coastal resources. A successful CBCRM Program in Mariveles should encourage the active participation of the primary utilizers of these marine resources, the marginalized fishermen, in policy formulation, implementation, and monitoring for a sustainable management and protection of finite marine resources.

Participatory, Effectiveness And Efficiency. The Cooperative Development Program (CDP) of the ISO, in organizing marginalized fishermen through the transfer of skills and technology, promoted a responsive and active citizenry facing the challenges of the loss of their livelihood. The ISO through a series of seminars and trainings had been successful in providing technical, logistical, paralegal and financial support for the various POs of Mariveles. It became the conduit for the marginalized fishermen to organize themselves into legitimate POs. It acted as a powerbroker between the Mariveles-LGU and the POs. The ISO also became the facilitator in building PO federations and in strengthening the capacity building of the marginalized fishermen through the transfer of community organizing skills, lobbying and persuasion skills, cooperative and leadership qualities, and social consciousness in the effective protection and efficient management of their finite marine resources.

In fact, a local fisherman observed that the primary lesson the marginalized fishermen and the BD-FARMCs have learned is capacity building. Through the trainings and seminars taught to them by the ISO, they have strengthened their capacity building to sustain a CB-CRM Program in Mariveles even in the absence of the ISO. The ISO confirmed this idea that community organizing was an effective tool in the promotion of a CB-CRM Program in Mariveles. The ISO by organizing the POs, in fact, strengthened their capacity building. This was a clear example of participatory governance, effectiveness and efficiency as indicators of eco-governance.

Rule Of Law, Preference For The Poor. The findings of the Participatory Rapid Appraisal (PRA), Resource Ecological Assessment (REA), and Legal Institutional Study (LIS) conducted by the ISO paved the way to address the main reasons why the marginalized fishermen had no sustainable livelihood. From these studies, the ISO found out that the finite marine resources of the Mariveles municipal waters were destroyed by large commercial fishing vessels using illegal fishing methods without recognizing the fifteen-kilometer municipal waters. Fortunately, the Philippine National Government was crucial in the success of the initiatives by the ISO, the POs, and the Mariveles-LGU. The Philippine Congress gave the legitimacy through the adoption of 
the Philippine Fisheries Code of 1998 (PFC) and the Local Government Code of 1991 (LGC). The Executive Branch through the Office of the President and Executive Order No. 240, Department of Agriculture, BFAR, PNP, provided the supplemental direction to implement a CB-CRM Program in Mariveles. Although there were some organizational and institutional problems, these National Government Agencies (NGAs) still opened the windows of opportunity for the Mariveles-LGU and the POs in making their own decisions. The Philippine Congress by legislating the Philippine Fisheries Code, it favored the POs over commercial fishers. The POs were given the equal opportunity under the law to utilize their finite marine resources. This was a clear example of the rule of law and preference for the poor as indicators of eco-governance.

Accountability And Transparency. The successful initiatives by the ISO through a CB-CRM Program in Mariveles and the cooperative efforts between the MarivelesLGU and the POs resulted in a principled partnership that would benefit different stakeholders. The absorption of the PO leaders inside the M-FARMC showed the importance of the role of the primary stakeholders in a CB-CRM Program. They are the direct beneficiaries of a CB-CRM Program so they should be involved in the formulation of municipal fishery ordinances. The institutionalization of the M-FARMC to the Mariveles-LGU based on principled partnership provided the sustainable management and protection of the finite coastal resources through the annual budget allocation from the Sangguniang Bayan (SB) of Mariveles. The role of the ISO was to act as a powerbroker to facilitate the principled partnership between the Mariveles-LGU and the marginalized fisherfolk for the promotion of a responsive and accountable CB-CRM Program.

As a consequence, the POs by actively participating in the M-FARMC, they were integrated into the Mariveles-LGU and they were empowered as partners in local development. Also, the POs were granted the space to formulate fishery ordinances in the M-FARMC. In addition, the SB of Mariveles by regularly providing municipal ordinances to the PO leaders, and by appropriating an annual budget allocation to the M-FARMC, it institutionalized the POs through the activities of the BD-FARMC. This was a good example of accountability and transparency as indicators of eco-governance.

\section{DISCUSSION}

The cooperative efforts of various stakeholders who formulated, implemented and monitored a successful CB-CRM Program in Mariveles in the sustainable management and conservation of their finite marine resources to promote good local ecogovernance led to the following findings.

First, POs and NGOs engage when NGOs can strengthen the POs' capacity building through the transfer of skills and technology, when NGOs can enhance the POs' indigenous knowledge, and when NGOs are more knowledgeable of formal venues of LGU participation. The cooperative efforts between the ISO and the POs in Mariveles through the process of community organizing and capacity building paved the success of a CB-CRM Program in the effective protection and efficient management of the finite coastal resources of Mariveles. Also, the ISO - BantayDagat (BD) or Baywatch Team collaboration led to the active participation of themarginalized fishermen of Mariveles who are the primary utilizers and beneficiaries of these finite marine resources. The ISO taught the marginalized fishermen of Mariveles how to influence or to make their presence felt through a series of seminars and trainings about PO organizing and capacity building. In addition, the recognition and awareness of the traditional practice of the POs' indigenous knowledge are important in the proper implementation of a CB-CRM Program. The conversion of the marginalized fishermen who used illegal fishing methods brought about by community organizing illuminates their progressive qualities and ingenuity as incomparable with the greedy 
qualities of the commercial fishers who have no sense of ownership and responsibility in the municipal waters of Mariveles. This proved that a CB-CRM Program in Mariveles was a clear example of participatory governance, effectiveness and efficiency.

Second, LGUs, NGOs and POs engage when POs and NGOs can complement each other to strengthen their capacity building, and when NGOs can help implement environmental programs that are beneficial to the POs. The participation between the Mariveles-LGU and the POs through the BantayDagat(BD) or Baywatch Team built a principled partnership among them. The ISO taught the BD-FARMC how to draft policies that affect their welfare and eventually, how to lobby these policies to the Sangguniang Bayan (SB) of Mariveles. The ISO was only a support mechanism in the effective protection and efficient management of the finite coastal resource base of Mariveles. Without the cooperative efforts of the Mariveles-LGU and the organized local fishermen through the formation of BDFARMCs and the allocation of funds by the SB, a CB-CRM Program could not be sustained. Also, by empowering the POs, this compensated the lack of political will of the Mariveles-LGU. The problem of the lack of political will, coming from both the National Government and the Mariveles-LGU, could be an impediment in the implementation of a CB-CRM Program. The M-FARMC which composed mainly of organized local fishermen or BD is already part of the system so this results to the irritant view of the LGU that they are now employees of the LGU. This is a lopsided opinion because these marginalized fishermen as primary utilizers and beneficiaries of a CB-CRM Program are still entitled to their own decisions to sustain the protection and management of their finite coastal resources. This proved that a CBCRM Program in Mariveles was a good example of accountability.

Third, NGOs and POs engage when POs are threatened by elite power, and when NGOs want their environmental issues on
LGU's legislative agenda. A CB-CRM Program in Mariveles led by the marginalized fishermen with the help of the ISO resulted in the adoption of the Philippine Fisheries Code (PFC), the creation of the Fisheries and Aquatic Resource Management Councils (FARMCs), and the formulation of municipal ordinances to protect the municipal waters from commercial fishing and illegal fishing methods. This proved that a CB-CRM Program in Mariveles was a clear example of the rule of law and preference for the poor.

Finally, NGOs and POs engage when they see possible LGU cooperation. The joint efforts of the POs and the Mariveles-LGU through the M-FARMC to institutionalize a CB-CRM Program resulted in the allocation of funds and the formulation of fishery ordinances by the Mariveles-LGU for the operations of the BD-FARMC in the proper implementation and monitoring of a CBCRM Program. This proved that a CB-CRM in Mariveles was a clear example of transparency.

\section{CONCLUSIONS}

1. POs and NGOs engage when NGOs can strengthen the POs' capacity building through the transfer of skills and technology, when NGOs can enhance the POs' indigenous knowledge, and when NGOs are more knowledgeable of formal venues of LGU participation.

2. LGUs, NGOs and POs engage when POs and NGOs can complement each other to strengthen their capacity building, and when NGOs can help implement environmental programs that are beneficial to the POs.

3. NGOs and POs engage when POs are threatened by elite power, and when NGOs want their environmental issues on LGU's legislative agenda.

\section{REFERENCES}

Alfiler, Ma. Concepcion (2003). Administrative Accessibility: Towards the 
Operationalization of a Concept. In: Bautista, Victoria et al, eds. (2003). Introduction to Public Administration in the Philippines: A Reader. Quezon City: University of the Philippines.

Bautista, Arnell (1993). Rules and Regulations Implementing the LocalGovernment Code of 1991. Manila: National Bookstore.

Brillantes Jr., Alex (2001). Developing Indicators of Local Governance in thePhilippines: Towards an "ISO" for LGUs. In: Brillantes, Alex, ed. PhilippineJournal of Public Administration vol. XLV, Nos. 1 \& 2 . Quezon City:University of the Philippines.
Mangada, Ladylyn (2004). Environmental Governance: The Case of San Pedro Bay, Philippines. In: Aguilar, Carmencita, ed. Environmental Protection and Regional Development. International Federation of Social Science Organizations.

Nolledo, Jose (2000). The 1991 Local Government Code with Basic Features. Manila: National Bookstore.

Rosal, Joseph (1999). Hayuma. Quezon City: Institute of Social Order.

World Commission on Environment and Development (1987). Towards Sustainable Development. Oxford University Press. 
